\title{
On Problem Based Learning and Application to Computer Games Design Teaching
}

\author{
http://dx.doi.org/10.3991/ijet.v7iS1.1909 \\ Olga Timcenko ${ }^{1}$ and Radoslav Stojic ${ }^{2}$ \\ ${ }^{1}$ Aalborg University, Copenhagen, Denmark \\ 2 Belgrade Metropolitan University, Belgrade, Serbia
}

\begin{abstract}
Problem-based learning is a pedagogical approach which started in early 1970s. It is well developed and established until now. Aalborg University in Denmark is one of pioneering world universities in PBL and has accumulated a huge experience in PBL for many different study lines. One of them is Medialogy education, which was established in 2002. This paper presents transfer of experiences from Medialogy education in Denmark to Game development education in Serbia - a new ( 2 years old) study line successfully developed in the country where game development companies hardly exist, but a need for newly educated programmers is evident.
\end{abstract}

Index Terms-Problem based learning; Project oriented learning, Computer games education

\section{INTRODUCTION}

Since its inception in early seventies by two newly founded Danish universities (Aalborg and Roskilde), Problem based learning has spread among many world universities [1].

In this paper we will very briefly present the main ideas of the Problem based learning and how it is implemented at Aalborg University in Denmark, which currently holds an UNESCO chair of problem-based learning [2].

We will illustrate this by describing PBL implementation to 9 years old, but now very popular and wellestablished Medialogy (Media technology) education, as well as the first promising experiences in implementing the PBL approach in teaching computer games in Serbia [3].

Namely, there is an increased interest among young population in South-East Europe for new media, virtual reality and game based technologies. In spite of lack of official university programmes, young people from the region often participate into various student competitions, frequently with significant success (for example, Imagine Cup). As a result, various educational courses were open, among them computer game design course at BMU (Belgrade Metropolitan University).

Having neither developed game industry in the region nor previous experience in teaching computer games, the following questions had to be answered:

- Which knowledge, technics and tools are suitable for the regional needs and still are compatible with the world leading game industry?

- Which methods to choose in teaching the subjects of rapidly evolving technology?
PBL approach and Aalborg University experience offered possibility for better student motivation and knowledge acquisition. Initial results of implementation of this method in teaching computer game design at BMU are described in this paper.

The paper is organized as follows:

- Aalborg PBL model is sketched in the Chapter2

- Chapter 3 presents Media Technology education

- In Chapter 4 examples of several recent students' projects on Medialogy education are described. The criteria for choosing the projects presented here was not that they were especially successful or wellexecuted, but that they were inspiring for BMU Game line education.

- BMU Game line education itself is described in the Chapter 5, followed by some of games' descriptions that students have developed during their project work in Chapter 6;

The closing, Conclusion chapter, summarizes two years of experience in implementing elements of PBL to a completely novel education in Serbia.

\section{PRoblem BASED LEARNING - AALBORg MODEL}

PBL is an ambiguous concept in international teaching and learning practice and literature. It can mean both problem-based and project-based learning, which are both well-established concepts.

However, even if we look at problem-based learning only, in spite of shared basic ideas, there are differences in practice between Danish universities (Roskilde from 1972 and Aalborg from 1974) and other universities worldwide (for example, Linköping in Sweden and Maastricht in the Nederland).

Before proceeding, let us see why we need PBL at all having in mind that classical teaching concept, existing over a centuries, may be used instead.

As it was pointed in [20]:

- Today's learner will have 10 to 14 jobs ... by the age of 40 !

- 1 out of 4 workers today is working for a company for whom they have been employed less than 1 year

- More than 1 out of 2 are working for a company for whom they have worked less than 5 years

- The top 10 jobs that will be in demand in 2012 didn't exist in 2000. 
So, the situation in engineering education is:

- We are currently preparing students for jobs that don't yet exist,

- using technologies that haven't yet be invented,

- in order to solve problems we don't even know are problems yet!

In this reality, problem based teaching approach, with its ability to teach many social, negotiation, groupworking and society-awareness skills to future engineers, seems to be a reasonable and promissing answer to current educational challenges.

This paper will concentrate on Danish model only [1], which builds on ideas of Illeris [4], among others, and works with the following principles:

- problem-orientation;

- project work;

- interdisciplinarity;

- participant directed learning;

- exemplary principle;

- team work.

Thus, Danish approach to PBL combines problembased and project-oriented approach, using problems as a starting point for learning in groups. The same model is implemented for all study-lines at the Aalborg University, from the first semester of Bachelor studies up to the 10th, graduation semester of Master studies. The model is under constant development and adjustment.

At the beginning, there has been lots of skepticism among educators, employers and public, but over the years a solid reputation has been established. An interesting data was released by Danish statistics in June 2010:

Ten years after graduation, Aalborg University graduates, on average, earn more than any other university graduates in Denmark [5]. This is taken as yet another strong indicator that problem based, project oriented pedagogical model is successful in practice.

Like on other, more classical universities, each semester consists of 30 ECTS. Those 30ECTS are divided into courses (typically 3 different courses 5ECTS each, combining different teaching methodologies), and 15ECTS group project work, with a common group exam, but with individual grades. The students formulate the problem for their project by themselves, constrained only by the semester theme. They need to back up their problem statement by state of the art research, proving that their problem is a real problem worth solving. Then they need to find the best possible solution, up to their skills and knowledge.

The question often raised by educators novel to PBL teaching is: "How do you assure that all group members give a significant contribution to the group work, learn enough and not pass the exam based on other group members' work?" The answer, proven by many years of practice and several research conducted among students [1], is that PBL is a real self-regulatory model: "Free-riders" (jargon for the members of the group who try to pass on the work of others) could survive the first, and, maybe, the second semesters - but then they have difficulties in getting accepted to any of the groups, as the students get to know each other very well. So the choice of those students is either to start working very hard for a semester, rebuild- ing a reputation, or quit the education, thus learning a very important life lesson.

So, in brief, the main characteristics of PBL are [1]:

- Learning is driven by challenging, open-ended, illdefined and ill-structured problems;

- Students generally work in collaborative groups.

- Teachers take on the role as "facilitators" of learning.

\section{MEDIA TECHNOLOgY (MEDiAlOgy) EdUCATION}

Aalborg University established Medialogy study line for the first time in fall 2002 at the faculty of Engineering and Natural Sciences. The idea was to offer a university education at bachelor, master and $\mathrm{PhD}$ levels in a combination of technical and humanistic subjects, like screen media, digital sound synthesis, sensor technology, perception, aesthetic, media sociology, computer graphics, human-computer interaction, interface design, etc., which would together enable the students to become "global problem-solvers in the technology world, independently on the problem"[8].

As it is stated on Medialogy web-presentation aimed for future students [7]:

"Medialogy focuses on education and research, which combine technology and creativity as means to design new processes and tools for art, design and entertainment - we do this to meet the requirements of our contemporary media industry. In authoring and designing Interactive Media, it is becoming increasingly evident that the largest challenge lies in bringing together different disciplines. Medialogy's interdisciplinary approach acknowledges that mastering and combining such a variety of disciplines requires a strong technical foundation, both in theory and in practice."

The educational approach is Problem Based Learning, [1], [6], as at all other studies at Aalborg University.

\section{MEDIALOGY STUDENTS’ PROJECTS EXAMPLES}

Three different Medialogy students’ projects will be described here. The first one is addressing mobile teaching of English for dyslectic adults, the second is a serious game challenging the concept of "First person shooter" games, and the third exploits challenges of technologyenhanced tools acceptance in the elementary-school classroom, and suggests the teachers' inclusion in development of such materials.

\section{A. Mobile learning example: I-phone application for dyslectic adults learning English}

This was a project on the first semester of Medialogy Masters studies in fall 2010. [9]

Introduction Danish dyslexic adults, learning English, need a tool that offers a possibility to practice foreign language outside a classroom. This project introduces a mobile application, designed for the iPhone and iPod Touch, as a possible solution to the problem. The application's design approach is inspired by the multi-sensory OrtonGillingham teaching method [10], which relies on combining audible, visual and haptic modalities to strengthen memorization. The iPhone and iPod Touch have been chosen as the interfaces for the application because they allow mobile multi-sensory interaction.

Method and Material: The application has been developed in collaboration with Capital School of Dyslexia in 
Copenhagen (Hovedstadens Ordblindeskole), where adult students are taught English with Holmberg's English Learning Program (HELP) [11].

HELP involves certain systematically structured spelling exercises and color codifications. At present, the students are unable to practice HELP outside the classroom without the teacher's participation. The design purpose of the application has therefore been to represent HELP and let the students continue the schoolwork by themselves in a natural and intuitive way.

A qualitative interview based field study, involving teachers and students, has been conducted at the school in order to examine the application's usability and representation of the HELP system.

An additional qualitative test has been conducted in order to examine how relevant video output, visualizing pronunciation, is for solving the spelling tasks.

Results and Discussion. The usability test showed that the application interface is intuitive and amusing to work with. Overall the users felt comfortable and familiar with the application layout. Due to its quiz based tasks and systematic visual structure, the application was accepted by students as an edutainment game. Hereby the students are offered a so far unavailable opportunity to continue their learning 'on the go' outside the classroom, using their iPhone/iPod Touch. Both teachers and students have emphasized the need for such a mobile application. Even in this early prototype state they showed strong enthusiasm towards the application, which indicates the relevance for further development.

\section{B. Serious games: First person victim}

This was a Master project defended in June 2010 [12]. Since then, it was presented at several conferences, for example [13], published as a book chapter [14], and used as a test-bed application for several experiments in virtual environments.

The problem statement is:

"What will you do when an air strike is announced, the attack is targeting your hometown, and you can hear the bombers coming nearer? How will you find your loved ones in the carnage after the explosions? What would it be like to be on the other side of the guns pointed at you by the invaders? What happens when we turn the roles around and the "First Person Shooter" becomes a "First Person Victim" experience?"

Scientific and psychological studies claim a variety of triggers in video games with violent content may promote aggression. To oppose the violent behavior of players in these games, this project investigates how the sources of aggression and first person shooter conventions could be exploited in the "First Person Victim" experience to create awareness about the consequences of war for civilians. An evaluation of the implemented experience indicated that the participants were engaged in the experience, despite the tragic theme, and that they were able to acquire an understanding of the theme being mediated.

\section{School applications}

Although there are many documented claims that educational games are beneficial for teaching, they are still not widely used in the classrooms.
There are many indicators that teachers' attitude is crucial for technology acceptance/refusal in educational practice. This students' project stated the problem [15]:

How to design an educational game with a didactic approach for pupils in elementary school, where the teachers are in focus of the development?

As a solution to this problem, a pilot study with local teachers from Ballerup commune was done during the cause of the semester. An user-centered innovation process was adopted.

The test shows that the approach of compiling empirical data from the teachers' experiences has been a success when developing a product used by the teachers. However, to make a conclusion upon a larger influence of increasing the use of educational games at elementary schools in Denmark, the students have concluded that there is a need for further tests. However, the prospective for using this approach for comply the lack of use of educational games are positive.

\section{Characteristics of $P B L$ projects}

Common characteristics of these three projects, as well as many other projects developed in PBL approach is engaging with real users, outside school, and solving real problems. However, many of Medialogy students' projects solve these real problems though a game development, which served as an inspiration for BMU.

\section{InTRoducing COMPuter Games Course AT BMU}

At BMU is applied classical teaching concept (fig 1), established in 2005 at Faculty of Information Technology (FIT) at a bachelor level.

Lectures are traditional presentation of facts, concepts and information about chosen subject. Worked examples are step by step demonstration how to solve typical problems related to subject and concepts explained at lectures.Assignments and student projects in form of independent individual problem solving allow students to verify and sharpen acquired knowledge.

Additionally, FIT pioneered in Serbia e-learning, for students not able to attend classes in a traditional way [16].

Recently, this study line was completed by master and $\mathrm{PhD}$ education levels, and following the same educational approach, BMU opened several new faculties, including faculty of management, faculty of digital arts and faculty of tourism and sport.

Also, a few years ago (2009) a module for Software Development for Computer Games was introduced at FIT

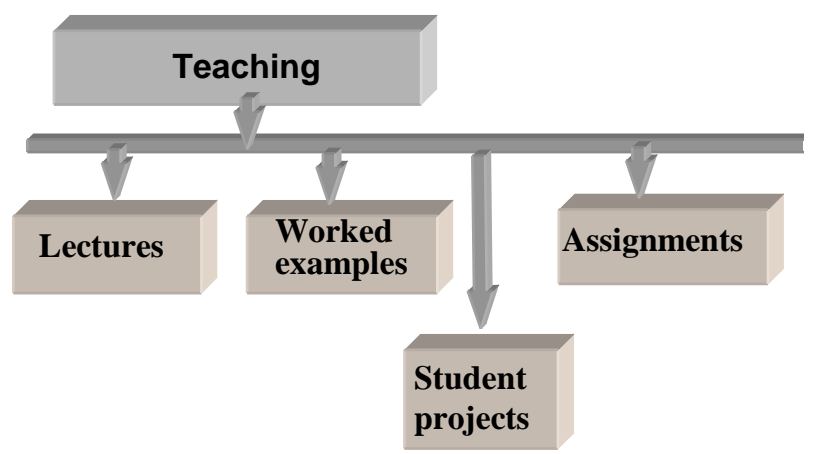

Figure 1. Traditional teaching model at BMU 
with the aim to fill in the gap, as there were no similar educations in Serbia. Due to the lack of previous experience in teaching computer games, and very modest game industry in the region, the following questions required special attention:

- Which knowledge, technics and tools are suitable for the regional needs and still are compatible with the world leading game industry?

- Which methods to choose in teaching the subjects of rapidly evolving technology?

\section{A. Analysis of Teaching Approach for Computer Games Course}

PBL is an attractive learning concept since it enables positioning students in a simulated real professional world, with tasks often not well defined and requiring original, creative and multidisciplinary approach. Students have to be active agents engaged in mutual work on common knowledge construction.

On the other hand, it is well recognised that this approach is not quite effective for beginners, especially if they need to process a lot of new information in a limited time. Especially for well-defined problems, students may spend more the time than necessary if they use PBL. In those cases studying worked examples becomes more effective [1].

Thus, traditional approach works well at initial and introductory study levels. Computer games (CG) course is taught at the final year of studies where students face real CG world tasks. Thus, prerequisites for applying PBL exist.

Unlike mathematics or programming languages and techniques, CG field is richer in various topics and less structured for study. In fact, games are imitations of what happens in real life [17]. Like simulations, they create illusion of reality often called virtual world.

For this reason there is not an unique theoretical discipline specific to computer games.

Even mathematical game theory is a discipline used to model and solve problems arising in economics, military and other fields which can hardly be considered as games. CG borrows knowledge and methodology from many scientific and engineering fields, like software engineering, mathematics, physics, artificial intelligence, robotics, psychology, sociology, aesthetics and others disciplines (fig 2).

It is not a priory obvious how to compose the basic knowledge units enabling students to create games within a context of traditional teaching approach.

Additional point to be considered is rapidly evolving software technology for compute games. Namely, a variety of IDE's and game engines API's exist and are under a constant development. The goal is to make game programming easier and to hide complexity of underlying methodologies, like non Euclidean geometry in computer graphics or finite element method for solving partial differential equations in cloth modelling.

PBL is adaptive approach capable of following rapid dynamics of game development community and offering advantages over traditional learning model.

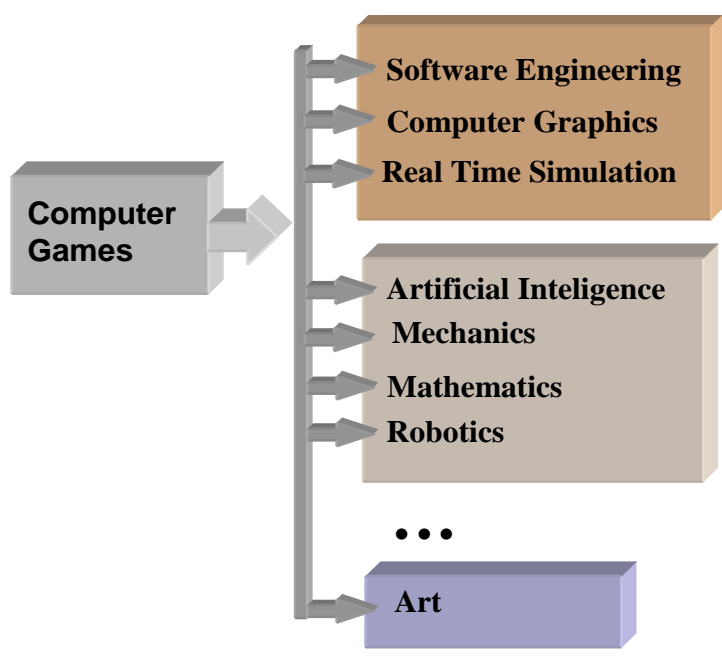

Figure 2. Theoretical base of Computer Games field

\section{B. Game Design Process and Teaching}

The basic characteristics of the games (goals, players, competition, and social role) are the same over the centuries. Art and procedure of computer game design may also be considered more or less stable over decades.

However, both computer hardware and ICT technologies are rapidly developing, and the educational process needs to take this specificity into account.

The educational concept is created as simulated game development process. It is assumed that game designer choses basic elements (goal, story, gameplay etc.) and then studies similar games, exploited platforms, techniques and tools (fig 3).

Final game is developed passing through various design steps and playable game versions, correcting (if necessary) several game elements at each stage, fig 4.

The study goal for each student is set to be development of his own playable game (one at least). Thus, the whole teaching and learning process is centred on chosen particular game to be the target game for a student or group of students.

The first step in study is to choose (with the aid of a teacher) the target game, which begins by studying the games from chosen genre (fig 3) and defining GDD (Game Design Document).

The target game development process is viewed as sequence of different versions, like in real life projects. At each stage GDD may be corrected to include new ideas and knowledge of student(s).

This sequence consists of elaboration of various game parts, like GUI development, character development, game AI, graphic assets etc. (Fig. 5)

After each stage (or development phase) the result is a new playable game version or playable module ready to be included in target game (Fig. 6).

The development phases are distributed over the assignments and projects in courses taught during game development studies.

Additionally the students are encouraged to participate in the game development club at BMU in order to present their results, get feedback from colleagues and to organise teams for student competitions. 


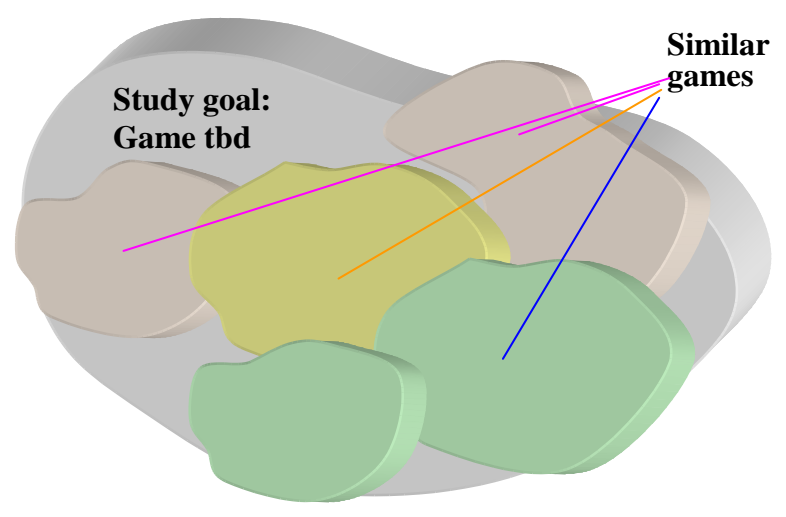

Figure 3. Target game (study goal) and exploration of similar games

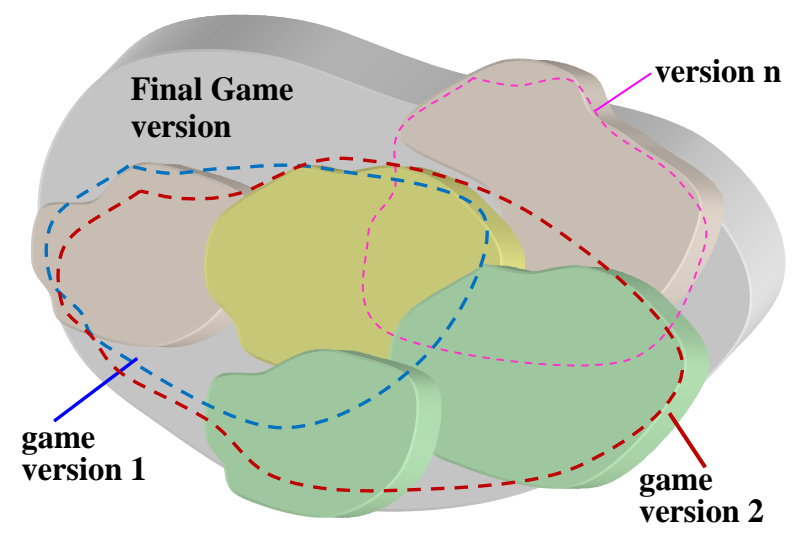

Figure 4. Playable versions preceding final game version

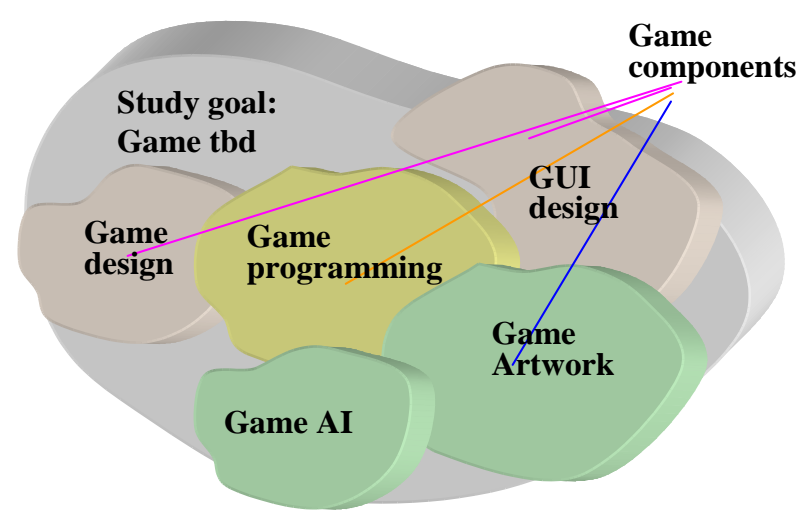

Figure 5. Target game components

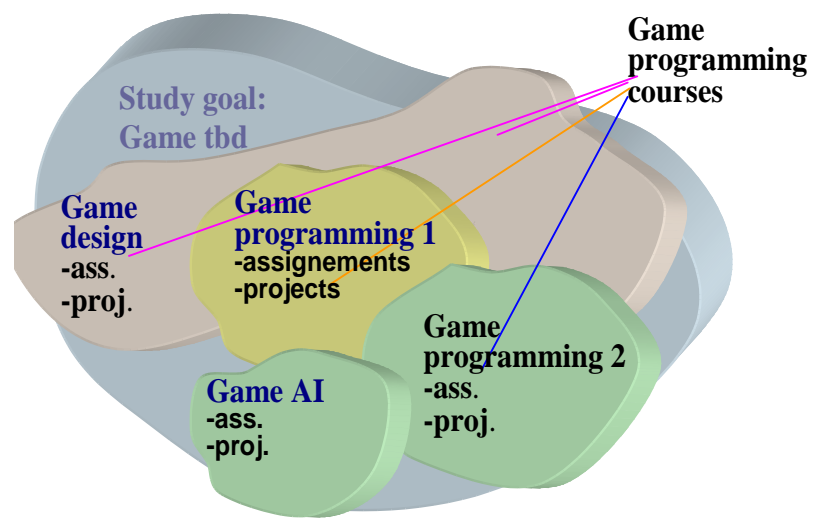

Figure 6. Repartition of the target game development into course projects and assignments

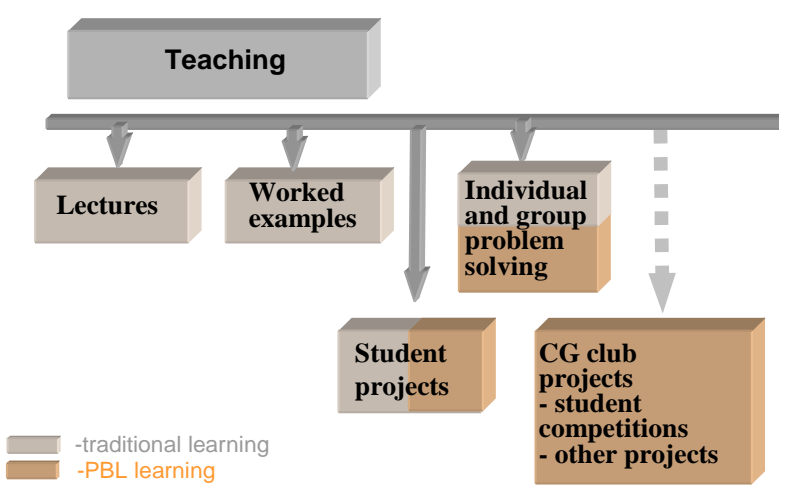

Figure 7. Combine teaching model for CG Course

\section{CG course implementation}

The course is implemented as follows.

First, the core techniques from game design, computer graphics, real time programming, artificial intelligence and mathematical modelling of motion are identified and put into traditional teaching model.

Working examples are composed in order to enable students to build simple 2D game using $\mathrm{C}++$ IDE and OpenGL API after one semester of studying. Doing homework, students confirmed acquiring knowledge. The following semester of the course focuses on the 3D game concepts, introducing 3D graphical modelling tools (Maya) and game engines (Unity 3D).

However, teamwork and group problem solving are added to individual work as a choice to students. Also, collaborative projects enabling several students to work on the same subject are introduced. In fact projects are individual, but share common goals, technics, and enable exchange of knowledge and results. In parallel to the student classes, the student game development club is initiated with the aim to build the games and participate at student competition like Imagine Cup.

Instructors also took a part in these activities, but only as advisors, leaving students to build the teams, to define projects and find their way to solve imposed tasks.

After the first semester the students have shown very good results - some of them may be seen at [16]. Since the site is in Serbian, a short description is given below.

A first game in the scope of the course was built before the end of the first semester as student project (fig 4).

The game is very simple, Tetris-like and combines three elements - fire, water and paper. Fire burns the paper, water extinguishes fire, paper absorbs water. The game is developed in Lua, inspired by student contacts with other gamers and teamwork in student club (Fig. 8).

The next project in the scope of Game AI, represents software environment for $\mathrm{C}++$ implementation and testing of guidance and obstacle avoidance algorithms (Fig. 9). It is based on Opensteer library and OpenGL graphics.

The first 3D game was developed as a part of student activity in the game development club, to take part in competition Imagine Cup (Fig. 10).

The robotised trash arrives from other galaxies and pollutes the schoolyard. The player is to clean the schoolyard finding right strategy to fight extra-terrestrials [19]. The game is developed in XNA framework (language C\#) for Windows and Xbox platforms. 


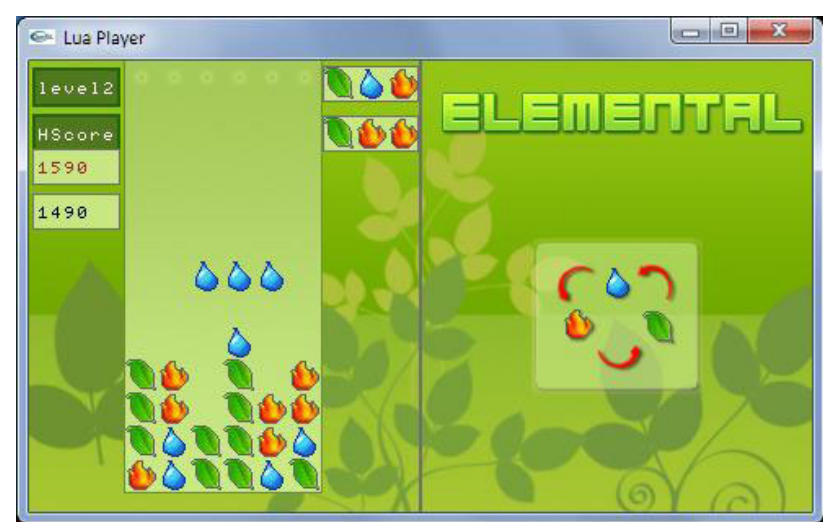

Figure 8. The first game in the course

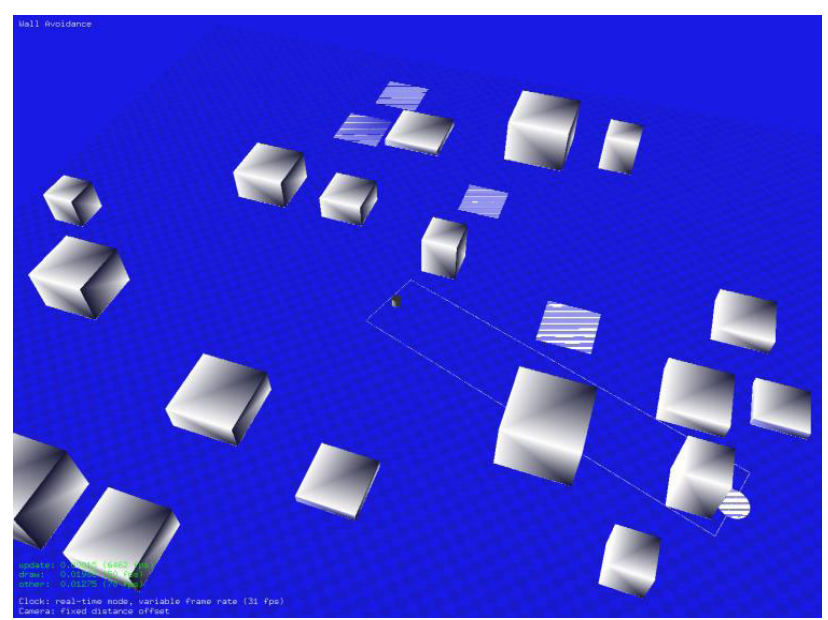

Figure 9. Environment for implementing intelligent agents

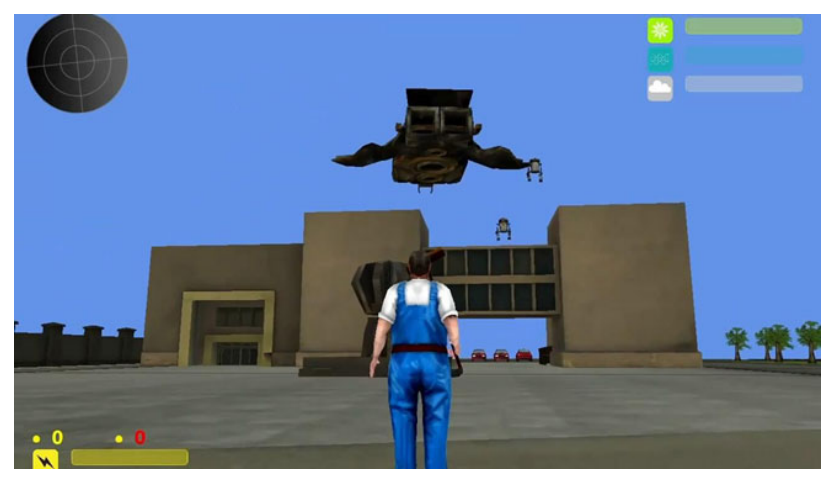

Figure 10. 3D game Janitor for Win and Xbox

The game was developed and submitted to competition before classes on 3D were finished. Also, XNA framework and C\# were beyond the scope of the classes - the students mastered them out of their shear intrinsic interest. This adds yet another evidence of the importance of problem based learning.

Other students' examples are mainly from artificial intelligence field, which has been very attractive for students form other modules. Namely the students found virtual environment very practical for developing and testing AI algorithms devoted for other (non-game) applications.

\section{CONCLUSION}

Aalborg approach in PBL has a long tradition; it is well established and, among many other study lines, applied to 9 years old Medialogy (Media technology) education.

It was found to be a promising strategy to increase effectiveness of the classical approach in teaching software development for computer games at BMU, Serbia. After two years of experience, PBL was found very useful in simulating conditions of real professional games world, facing the students with teamwork aspects, mutual competition and promoting creativity and action.

The positive feedback of the PBL approach on the traditional learning line was also noted. Mutual collaboration helped students to make concepts clear with less (or no) help of instructor. Also, often the students propose their own way to solve the problems and in the majority of cases the students' proposals were more elegant and effective.

\section{REFERENCES}

[1] A.Kolmos, F.K.Fink, L.Krogh, "The Aalborg PBL Model - Progress, Diversity and Challenges”, Aalborg University Press, 2004

[2] http://vbn.aau.dk/da/organisations/unesco-chair--problem-basedlearning(a77a51e4-88b6-46bd-944e-54d639be4432).html

[3] Timcenko O., Stojic R., "On the Aalborg University Problem based learning model and application to teaching computer games", The Second International Conference on e-Learning (eLearning-2011), 29-30 September 2011, Belgrade, Serbia

[4] Illeris, Knud. Problemorientering og deltagerstyring. Oplæg til en alternativ didaktik. Munksgaard, Copenhagen. 1974. (Problem orientation and data organization: A proposal for an alternative didactisc)

[5] http://www.information.dk/235718, visited 23/08/2011

[6] Moesby, E, "From Pupil to Student - a Challenge for universities: an example of a PBL study programme”, Global J. of Engng. Educ., Vol.6, No.2 (c) 2002 UICEE

[7] Medialogy web-site, http://www.cvmt.dk/Medialogi/medialogi. html, (visited 23rd August, 2011)

[8] Nordahl, R. and Serafin, S., (2004) Medialogy: a bridge between technology and creativity based on the Aalborg Model. International Computer Music Conference, Miami, Florida

[9] R.Yanakieva, J. Shelepin, C. Gjelstrup,T. N. Poulsen, „Breaking The Classroom Boundaries: An Iphone Application For Dyslexic Adults Learning English”, 5th 7SEMCON, Aalborg University Copenhagen, December 2009

[10] Teaching Methods That Work. http://www.dys-add.com. [Online] Bright Solutions for Dyslexia, Inc., 1998. http://www.dysadd.com/teach. html\# ogmethod

[11] Engelskundervisning for ordblinde. Nyrop, Lise-Marie and and Olsen, Martin Hauerberg 2009. In Ordblindhed March 2009, nr 62 http://www.dvo.dk/index.php?id=453.

[12] Jawid Faizi, Faysal Fuad Khalil "Engagement in Interactive Drama”, Medialogy Master Thesis, Aalborg University Copenhagen, 2010

[13] Henrik Schoenau-Fog, Luis Emilio Bruni, Faysal Fuad Khalil and Jawid Faizi: „First Person Victim - Using Tragedy and Engagement to Create Awareness about the Consequences of War", Meaningful Play 2010 Conference Proceedings, Michigan University Press

[14] Henrik Schoenau-Fog, Luis Emilio Bruni, Faysal Fuad Khalil and Jawid Faizi „First Person Victim: Developing a 3D Interactive Dramatic Experience“, Interactive Storytelling, Lecture Notes in Computer Science, 2010, Volume 6432/2010, 240-243, DOI: 10.1007/978-3-642-16638-9_32

[15] Charina B. S. Hansen, „Designing an Educational Game - from a Teacher-centred Perspective“, Masters Thesis, Aalborg University 2011

[16] Metropolitan - Courses Description (in Serbian), http://www.me tropolitan.edu.rs/sr/osnovne_studijevisited 30/08/2011. 
[17] Crawford, C. „Chris Crawford on Game Design“, Prentice Hall, 2003

[18] Metropolitan - Software development for CG (in serbian) http://www.metropolitan.edu.rs/sr/osnovne_studije/fakultet_infor macionih_tehnologija/razvoj_softvera_za_racunarske_igre.dot, visited 30/08/2011

[19] The Janitor - Imagine Cup 2011 Game Design, http://www.you tube.com/watch?v=2-YAzA6_2mI, visited 30/08/2011

[20] Michael E. Auer „IGIP and the Global Trends in Learning and in Engineering Education”, Keynote, IGIP Conference 2011, Santos, Brazil

\section{AUTHORS}

O. Timcenko is with the Aalborg University, Copenhagen, Lautrupvang 15, Ballerup, Denmark (e-mail: ot@create.aau.dk).

R. Stojic, is with Faculty of Information Technologies, Belgrade Metropolitan University, Tadeusa Koscuska 63, Belgrade, Serbia (e-mail: radoslav.stojic@fit.edu.rs)

This article is a modified version of a paper presented at the Second International Conference eLearning 2011, held in October 2011, at Metropolitan University in Belgrade, Serbia. Received 19 December 2011. Published as resubmitted by the authors 8 February 2012. 